\title{
Otimização multi-objetivo de estações de tratamento DE ÁGUAS DE ABASTECIMENTO: REMOÇÃO DE TURBIDEZ, CARBONO ORGÂNICO TOTAL E GOSTO E ODOR
}

\section{MULTI-OBJECTIVE OPTIMIZATION OF WATER TREATMENT PLANTS: TURBIDITY, TOTAL ORGANIC CARBON AND TASTE \& ODOR REMOVAL}

\begin{abstract}
SIDNEY SECKLER FERREIRA FILHO
Engenheiro Civil pela EPUSP. Mestre e Doutor em Engenharia Civil pela EPUSP. Professor Associado do Departamento de Engenharia Hidráulica e Sanitária da Escola Politécnica da Universidade de São Paulo

\section{MARGARIDA MARCHETTO}

Pesquisadora Pós-Doutoranda do Departamento de Engenharia Hidráulica e Sanitária da Escola Politécnica da Universidade de São Paulo em regime de dedicação integral a docência e a pesquisa

Recebido: 16/05/05 Aceito: 25/10/05
\end{abstract}

\begin{abstract}
RESUMO
Normalmente, as estações de tratamento de água (ETA’s) tem objetivado à otimização de remoção de turbidez, cor aparente, bem como a produção de uma água segura do ponto de vista microbiológico. No entanto, em face de novos desafios técnicos, os objetivos a serem atingidos tem sido mais abrangentes. Deste modo, este trabalho teve por propósito estudar a otimização da ETA Rio Grande, definindo as suas condiçōes de operação que tenha por objetivo a maximização da remoção de turbidez, compostos orgânicos naturais (CONs) e gosto e odor. Concluiu-se que a coagulação operada na faixa de $\mathrm{pH}$ entre 5,8 e 6,5 permite tanto a otimização da remoção de turbidez, mas também de CONs. A remoção de gosto e odor por adsorção apresentou-se ser independente do $\mathrm{pH}$ e, assim sendo, os objetivos de otimização da operação da ETA Rio Grande mostraram-se viáveis tecnicamente.
\end{abstract}

PALAVRAS-CHAVE: Tratamento de água, adsorção, remoção de cor e turbidez, carvão ativado, gosto e odor.

\section{INTRODUÇÃO}

Tradicionalmente, o projeto de estações de tratamento de água convencionais para o tratamento de águas de abastecimento tem considerado como principais objetivos a otimização dos processos de remoção de material particulado e cor aparente, bem como a produção de uma água segura do ponto de vista microbiológico e químico.

No entanto, devido à escassez de água em regiôes metropolitanas e, associado ao fato de que a maior parte dos mananciais utilizados para abastecimento público de sistemas de grande porte tem como origem reservatórios de acumulação que se encontram em elevado estado

\section{ABSTRACT}

Traditionally, the design of conventional water treatment plants (WTP's) has considered turbidity and color removal as well as the production of microbiologically safe water as primary goals regarding treatment optimization. In face of new technical challenges, the water quality objectives that must be achieved are far reaching. The purpose of this paper was to study the optimization of Rio Grande WTP in order to define the optimum operating conditions with respect to coagulation which maximize turbidity, natural organic matter (NOM) and taste and odor removal. The experimental results indicated that the coagulation $\mathrm{pH}$ in the range 5.8 to 6.5 led to both turbidity removal and NOM removal optimization. In addition to that and regardless of the $\mathrm{pH}$ range, taste and odor removal by adsorption was satisfactory. Therefore, the optimization of Rio Grande WTP is technically feasible.

KEYWORDS: Water treatment, adsorption, color and turbidity removal, activated carbon, taste and odor. de eutrofização, a dimensão dos problemas e desafios a serem enfrentados atualmente pelos profissionais do setor é significativa, especialmente para estaçóes de tratamento de água (ETA's) já existentes e que encontram dificuldades na incorporação de processos e operações unitárias adicionais.

A Figura 1 apresenta uma visão multi-objetivo de uma estação de tratamento de água, considerando alguns dos problemas ambientais mais significativos a serem defrontados quando do seu projeto e operação.

Do ponto de vista prático, uma das primeiras etapas do projeto de um sistema de abastecimento de água é a seleção do manancial que, preferencialmente, deve atender a critérios de quantidade e qualidade mínimas requeridas quando de sua utilização para fins de potabilização. Com respeito ao aspecto qualitativo, historicamente, os mananciais empregados para abastecimento público sempre foram escolhidos de modo a possibilitar que as ETA's fossem do tipo convencionais ou uma variante desta (filtração em linha ou filtração direta).

Assim sendo, os seus principais objetivos a serem atendidos era a produção de água potável no tocante ao Padrão de Potabilidade para cor e turbidez e que fosse segura do ponto de vista microbioológico e químico. Como a grande maioria dos sistemas de abastecimento no Brasil possui mais de 30 anos de vida útil 
e tendo sido este o principal delineador na concepção das estaçóes, a maior parte destas atualmente em operação é do tipo convencional.

No entanto, no ano de 1974, alguns pesquisadores descobriram que a reação do cloro com determinados compostos orgânicos naturais (CONs) poderia formar compostos orgânicos halogenados (Rook, 1976; Bellar et al, 1976). Dentre estes, os que estão presentes em maiores concentraçôes em águas de abastecimento, quando submetida ao processo de desinfecção com o cloro, são os compostos classificados como trihalometanos (clorofórmio, bromofórmio, diclobromometano, dibromo-clorometano) e os ácidos haloacéticos (ácido monocloroacético, dicloroacético, tricloroacético, monobromoacético e dibromoacético).

Tendo por propósito reduzir a formação de trihalometanos (THMs) e ácidos haloacéticos (AHAs) em águas de abastecimento, podem ser identificadas três linhas de atuação, a saber (Singer, 1994):

- Remoção dos compostos orgânicos precursores de subprodutos da desinfecção em águas de abastecimento.

- Alteração do ponto de aplicação do agente desinfetante, mudança do agente desinfetante ou uma combinação de ambos.

- Remoção dos compostos orgânicos halogenados totais, uma vez formados durante o processo de desinfecção.

Em face dos novos desafios impostos no tocante à minimização da formação de subprodutos da desinfecção (SPD), diferentes técnicas têm sido empregadas para tal, sobressaindo-se a maximização de remoção de CONs pelo processo de coagulação, por ser esta uma operação unitária já integrante de ETA's convencionais e suas variantes, bem como a utilização de agentes oxidantes alternativos.

A partir de então, a operação dos processos unitários componentes do tratamento convencional de águas de abastecimento passou a ter de contemplar, não apenas a produção e fornecimento de água com padrôes estéticos adequados e isenta de microrganismos patogênicos, como também tendo que minimizar a formação de compostos orgânicos sub-produtos da desinfecção.

Historicamente, até 1974, o controle da concentração de CONs em águas de abastecimento teve sempre por pro-

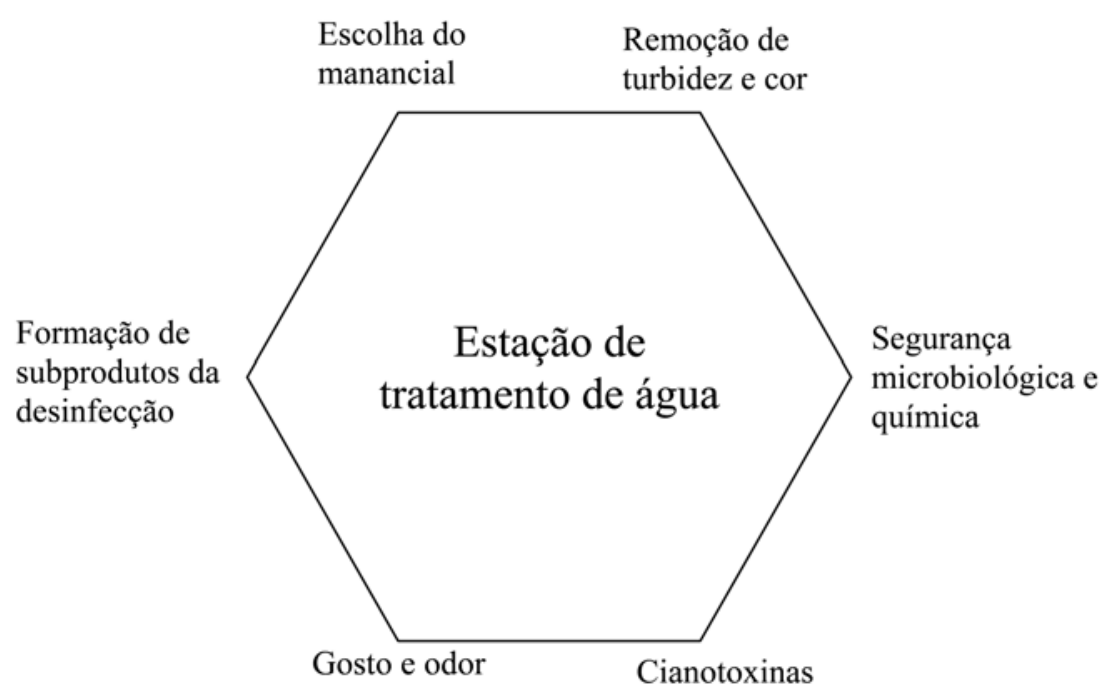

Figura I - Funções multi-objetivos envolvidos no projeto e operação de uma estação de tratamento de água

pósito reduzir a cor real visando a produção de uma água final esteticamente adequada para fins de consumo. Dado que as águas naturais podem conter significativas concentrações de CONs que não tenham a propriedade de transmitir luz visível e que, consequentemente, não proporcionam cor real, mas que possam ser precursores de sub-produtos da desinfecção, o seu controle passou a ser muito mais difícil e oneroso.

A maximização do aumento da remoção de CONs durante o processo de tratamento pode ser benéfico não apenas com a finalidade de minimização da formação de SPD, como também possibilitar a redução na demanda de cloro e do potencial de crescimento de biofilmes no sistema de distribuição.

Esta maximização da remoção de CONs pode ser conseguida mediante $\mathrm{o}$ controle do processo de coagulação por meio de seu pH e dosagens adequadas de coagulante (Frederico et al, 1999; Garzuzi et al, 1999). No entanto, há inconvenientes em aumentar a dosagem do coagulante em ETA's convencionais, podendo-se citar o aumento do volume de lodo gerado, as instalações para armazenamento de produtos químicos podem não ser adequadas, a remoção de turbidez pode não ocorrer na mesma condição que permita a otimização da remoção de CONs e, finalmente, aumento do custo total de produtos químicos empregados na coagulação e ajuste final de $\mathrm{pH}$.

Como a maior parte das estações pertencentes a sistemas de abastecimento de água localizados em regióes metropolitanas possuem como manancial reserva- tórios de acumulação que, muitas vezes, recebem uma elevada carga de nutrientes oriundos de lançamento de esgotos sanitários em estado bruto, muitos destes apresentam elevado grau de eutrofização, com significativos problemas de gosto e odor e eventual presença de cianotoxinas.

Tradicionalmente, a melhor alternativa para a remoção de compostos orgânicos causadores de gosto e odor em águas de abastecimento tem sido a aplicação de carvão ativado em pó (CAP), podendo este ser aplicado junto à captação de água bruta ou juntamente com o coagulante na mistura rápida (Sontheimer et al, 1988).

No entanto, uma vez que o processo de adsorção não é seletivo na remoção de compostos orgânicos presentes na fase líquida, o CAP pode remover não somente os compostos orgânicos causadores de gosto e odor, como também os demais presentes na fase líquida, notadamente os CONs. Estes, ao serem adsorvidos pelo CAP, reduzem a sua capacidade de adsorção, sendo necessário aumentar a dosagem de CAP a fim de que seja possível atingir uma determinada eficiência de remoção.

Portanto, na eventualidade de uma ETA necessitar efetuar a aplicação de CAP para controle de gosto e odor, a otimização na remoção de $\mathrm{CON}$ s pode ser altamente benéfica por permitir também a otimização do processo de adsorção.

Observando-se a Figura 1, pode-se notar que, muitas vezes, os objetivos que uma ETA tem que atingir são conflitantes entre si, não existindo necessariamente uma condição ótima de operação que 
maximize todos ao mesmo tempo. Para uma situação em que os objetivos a serem atingidos sejam unicamente a otimização de ambos os processos de remoção de turbidez e cor e desinfecção, as condições ótimas de operação da ETA não são conflitantes e a otimização do processo de tratamento passa a ser relativamente simples.

No entanto, com a crescente demanda de objetivos a serem atingidos, muitas vezes a condição ótima de remoção de turbidez não é a mesma que permite a maximização de CONs. Em sendo assim, sob certas condições de operação dos processos de pré-oxidação e desinfecção, pode ocorrer sazonalmente a formação de THMs em concentrações superiores ao Padrão de Potabilidade vigente.

A eventual ocorrência de gosto e odor resultante da presença de subprodutos metabólicos de algas e demais microrganismos na água bruta pode demandar a aplicação de CAP e este pode ter a sua eficiência reduzida com respeito a remoção de gosto e odor caso esteja também na presença de CONs.

Um dos melhores exemplos de situação em que tais desafios são apresentados na operação de ETA's é a Região Metropolitana de São Paulo (RMSP). O sistema produtor da RMSP é composto por oito estaçôes, sendo que seis destas possuem como manancial reservatórios de acumulação com os mais diversos estados de eutrofização. Deste modo, a otimização dos processos de tratamento de um ponto de vista multi-objetivo faz-se necessário dado que as pressôes da opinião pública e ambientais têm sido cada vez mais significativas e o Padrão de Potabilidade mais restritivos.

\section{OBJETIVOS}

Tendo em vista o exposto, o principal objetivo deste trabalho foi estudar a otimização da ETA Rio Grande, localizada na RMSP, pertencente e operada pela SABESP, tendo sido avaliados os processos de coagulação química e adsorção em CAP. Os principais aspectos considerados foram, a saber:

- Definição das condições ótimas de operação do processo de tratamento de água (dosagem de coagulante e CAP) que tenha por objetivo a maximização da remoção de turbidez, CONs e MIB.

- Avaliação da influencia do pH e da dosagem do coagulante na remoção de compostos orgânicos naturais (CONs) e turbidez.
- Otimização do processo de adsorção em CAP na remoção de compostos orgânicos causadores de gosto e odor (MIB) quando em presença de CONs.

\section{MATERIAIS E MÉTODOS}

\section{Generalidades}

A pesquisa foi desenvolvida empregando-se a água bruta que abastece ao Sistema Produtor Rio Grande, localizado em São Bernardo do Campo, pertencente e operado pela SABESP. O Sistema Produtor Rio Grande entrou em operação em 1.958, com uma capacidade nominal de $0,6 \mathrm{~m}^{3} / \mathrm{s}$, com tratamento convencional. Em 1.968, o sistema foi ampliado com o objetivo de aumento da capacidade de tratamento de $0,6 \mathrm{~m}^{3} / \mathrm{s}$ para $1,45 \mathrm{~m}^{3} / \mathrm{s}$ e, para tanto, foram construídas na estação novas unidades de floculação, decantação e filtração, tendo a mesma, no final de sua ampliação, um total de 7 floculadores, 7 decantadores e 14 filtros rápidos de areia.

Ao mesmo tempo em que diversas atividades foram desenvolvidas tendo por objetivo principal propiciar o aumento da capacidade de tratamento do Sistema Produtor Rio Grande, também foram implementadas um conjunto de obras hidráulicas que permitiram a preservação e melhoria da qualidade da água na captação de água bruta. Dentre estas, ressaltam-se as obras de fechamento do Braço do Rio Grande do Reservatório Billings, isolando-se hidraulicamente ambos os corpos d'água, o que permitiu uma melhoria significativa da qualidade da água bruta captada pelo Sistema Produtor Rio Grande, uma vez tendo sido atenuada a influência do bombeamento e reversão do Rio Pinheiros para o Reservatório Billings.

Os principais problemas de qualidade da água atualmente existentes no Reservatório do Rio Grande residem no fato de receber uma grande carga de esgotos sanitários sem tratamento proveniente da cidade de Ribeirão Pires, o que tem causado um aumento no grau de eutrofização do corpo d'água. Este aumento no grau de eutrofização do Reservatório do Rio Grande tem causado dificuldades na operação da ETA devido a um aumento na concentração de algas na água bruta durante determinados períodos do ano, exigindo uma maior aplicação de coagulante, dosagem de CAP para controle de gosto e odor e aumento das dosagens de agente oxidante. Atualmente, a ETA trata uma vazão de $4,5 \mathrm{~m}^{3} / \mathrm{s}$, sendo responsável pelo abastecimento de cerca de $8 \%$ da população da Região Metropolitana de São Paulo (RMSP), tendo previsão de ampliação para $8,0 \mathrm{~m}^{3} / \mathrm{s}$.

Os ensaios foram realizados no Laboratório da respectiva ETA, tendo-se executado ensaios de jarros com o propósito de definir as condições ótimas de operação do processo de tratamento de água (dosagem de coagulante e CAP) que tenha por objetivo a maximização da remoção de turbidez, CONs e MIB. Como parâmetro empregado para avaliar a concentração de CONs na fase liquida, foi empregado o parâmetro carbono orgânico dissolvido (COD).

Os problemas de gosto e odor presentes na água bruta que abastece a ETA Rio Grande são, principalmente, oriundos de subprodutos metabólicos de algas e demais microrganismos, pelo fato do manancial apresentar elevado grau de eutrofização. Os compostos orgânicos MIB e Geosmina tem sido preponderantemente os mais identificados e, pelo fato da Geosmina ser de mais fácil remoção por processos de adsorção quando comparado com o MIB, este foi o parâmetro de avaliação empregado quando executados os ensaios de adsorção em CAP (AWWARF, 2000).

Uma vez que, durante o período de investigação experimental, a água bruta utilizada nos ensaios experimentais poderia não conter o composto MIB, este foi adicionado à mesma, de modo que $\mathrm{a}$ sua concentração na fase líquida situasse entre 200 ng/L a 400 ng/L, valores estes representativos da água bruta proveniente do manancial quando dos episódios de gosto e odor mais significativos. Portanto, para cada ensaio executado era adicionada alíquota de padrão de MIB (Wako Chemicals), fim de conferir a água bruta a concentração desejada.

O CAP empregado na investigação experimental é de origem nacional (Brascarbo Agroindustrial Ltda CarboActiv K), de origem vegetal e apresentando número de iodo mínimo de $600 \mathrm{mg} / \mathrm{g}$. A justificativa para a sua escolha é o fato de que o mesmo é empregado rotineiramente na ETA Rio Grande para controle de gosto e odor.

Com o intuito de facilitar o entendimento dos procedimentos experimentais realizados, a Tabela 1 apresenta um resumo dos ensaios de adsorção realizados, com anotações das condiçôes de cada ensaio, concentraçôes de MIB e COD. 
A Tabela 2 apresenta as características das águas brutas do Sistema Produtor Rio Grande (Represa Billings) referente as diversas etapas da investigação experimental.

\section{Procedimentos experimentais}

O procedimento experimental consistiu de ensaios de jar-test, em que foram variadas as dosagens de coagulante e $\mathrm{pH}$ de coagulação. O coagulante empregado foi o sulfato férrico comercial $\left(\mathrm{Fe}_{2}\left(\mathrm{SO}_{4}\right)_{3}\right)$, pelo fato deste ser empregado regularmente na ETA Rio Grande.

Os ensaios foram conduzidos com CAP previamente definido, com dosagem fixa de $30 \mathrm{mg} / \mathrm{l}$, com adição $1 \mathrm{mi}$ nuto antes do coagulante, estando a fase líquida em agitação. Foi utilizado um polímero como auxiliar de floculação, com dosagem igual a $0,02 \mathrm{mg} / \mathrm{l}$, marca CIBA Magnafloc LT 20. A Figura 2 apresenta um fluxograma com os ensaios experimentais conduzidos.

Inicialmente, a água bruta era disposta em uma caixa de cimento-amianto de capacidade igual a 50 litros. Procedia-se então a introdução de MIB na água bruta com o auxilio de uma micro-seringa, a fim de obter concentração inicial do adsorvato na faixa de $200 \mathrm{ng} / \mathrm{L}$ a $400 \mathrm{ng} / \mathrm{L}$. A homogeneização da água bruta e do adsorvato era efetuada com o auxilio de um agitador mecânico de alta capacidade com rotação igual a $300 \mathrm{rpm}$, para que os sólidos em suspensão presente na água bruta permanecessem na fase líquida e fosse evitada a volatilização de MIB para a fase gasosa.

Após 10 minutos de homogeneização eram coletadas amostras de água bruta em duplicata para a determinação da concentração de MIB e COD, sendo posteriormente transferidos dois litros da mesma para cada jarro do equipamento de jar-test. A solução do coagulante era preparada no início de cada ensaio com concentração de $5 \mathrm{~g} \mathrm{Fe}_{2}\left(\mathrm{SO}_{4}\right)_{3} / \mathrm{L}$. A rotação do sistema de agitação para mistura rápida foi mantida a um valor em torno de $300 \mathrm{rpm}$ e a aplicação da suspensão de CAP realizada simultaneamente em todos os jarros.

Imediatamente após a mistura rápida, reduzia-se a rotação do sistema de agitação de modo a permitir a simulação do processo de floculação, tendo os mesmos gradientes de velocidade iguais a $70 \mathrm{~s}^{-1}, 50 \mathrm{~s}^{-1} \mathrm{e}$ $30 \mathrm{~s}^{-1}$ e tempo total de 15 minutos. Estes valores de gradientes de velocidade e tempo de floculação foram adotados por ser os empregados na operação da ETA Rio Grande. Decorrido este tempo, desligava-se o sistema de agitação e aguardava-se a sedimentação dos flocos (2,7 minutos) para a correspondente coleta de amostras de água decantada representativa para as taxas de escoamento superficial dos decantadores em operação na respectiva ETA Rio Grande. (Di Bernardo et al, 2002).

Tabela I - Ensaios realizados com água bruta do Braço do Rio Grande (Reservatório Billings) com adição de MIB

\begin{tabular}{|c|c|c|c|c|c|c|}
\hline \multirow{2}{*}{\multicolumn{2}{|c|}{ Ensaio }} & \multicolumn{3}{|c|}{ Condições dos ensaios } & \multirow{2}{*}{$\begin{array}{c}\text { Concentração } \\
\text { de MIB na } \\
\text { água bruta } \\
\text { (ng/l) }\end{array}$} & \multirow{2}{*}{$\begin{array}{c}\text { Concentração } \\
\text { de COD na } \\
\text { água bruta } \\
(\mathrm{mg} / \mathrm{l})\end{array}$} \\
\hline & & $\begin{array}{l}\text { Dosagem de coagulante } \\
\qquad \mathrm{Fe}_{2}\left(\mathrm{SO}_{4}\right)_{3}(\mathrm{mg} / \mathrm{l})\end{array}$ & $\begin{array}{c}\mathrm{pH} \text { de } \\
\text { coagulação }\end{array}$ & CAP & & \\
\hline 01 & $\begin{array}{c}\text { com e } \\
\text { sem CAP }\end{array}$ & $\begin{array}{c}\text { Variaçãao } \\
(5,0 \text { a } 50,0)\end{array}$ & $\begin{array}{l}\text { Variação } \\
(4,5 \text { a } 9,3)\end{array}$ & $\begin{array}{c}\text { Para os } \\
\text { ensaios com }\end{array}$ & $214 ; 233$ e 315 & 3,3 a 4,0 \\
\hline 02 & $\begin{array}{c}\text { com e } \\
\text { sem CAP }\end{array}$ & & & $\begin{array}{c}\text { CAP } \\
\text { dosagem fixa }\end{array}$ & $209 ; 165$ e 241 & 4,3 a 5,3 \\
\hline 03 & $\begin{array}{c}\text { com e } \\
\text { sem CAP }\end{array}$ & & & $\begin{array}{c}(30 \mathrm{mg} / \mathrm{l}) \\
\text { Tempo de } \\
\text { contato }\end{array}$ & 414 & 3,8 e 3,9 \\
\hline 04 & $\begin{array}{c}\text { com e } \\
\text { sem CAP }\end{array}$ & & & $(16 \mathrm{~min})$ & 574 & 4,3 e 4,5 \\
\hline
\end{tabular}

Tabela 2 - Características da água bruta do sistema produtor Rio Grande (Represa Billings) referente as diversas etapas de pesquisa

\begin{tabular}{|c|c|c|c|c|}
\hline \multirow[t]{2}{*}{ Parâmetros } & \multicolumn{4}{|c|}{ Ensaios } \\
\hline & 01 & 02 & 03 & 04 \\
\hline Turbidez (UNT) & 2,0 a 4,0 & 1,3 a 1,4 & 3,0 a 3,5 & 2,0 a 2,6 \\
\hline $\mathrm{pH}$ & 6,9 a 7,2 & 7,1 & 7,1 a 7,4 & 6,7 a 6,8 \\
\hline Cor aparente (UC) & 25 a 40 & 20 & 53 a 70 & 30 a 45 \\
\hline Temperatura ${ }^{\circ} \mathrm{C}$ & 21 a 24 & 16 a 19 & 20 a 21 & 23 a 24 \\
\hline COD (mg/L) & 3,4 a 4,0 & 3,9 a 5,3 & 3,8 & 3,8 a 4,4 \\
\hline MIB (ng/L) & 214 e 315 & 165 e 241 & 414 & 59 e 574 \\
\hline Ferro $(\mathrm{mg} / \mathrm{L})$ & 0,3 & 0,06 a 0,09 & 0,15 a 0,20 & 0,37 a 0,57 \\
\hline Manganês (mg/L) & - & 0,05 a 0,08 & 0,09 a 0,21 & 0,23 \\
\hline Alcalinidade $\left(\mathrm{mg} / \mathrm{L}\right.$ de $\left.\mathrm{CaCO}_{3}\right)$ & 19 & 18 a 20 & 20 a 22 & 22 a 24 \\
\hline
\end{tabular}




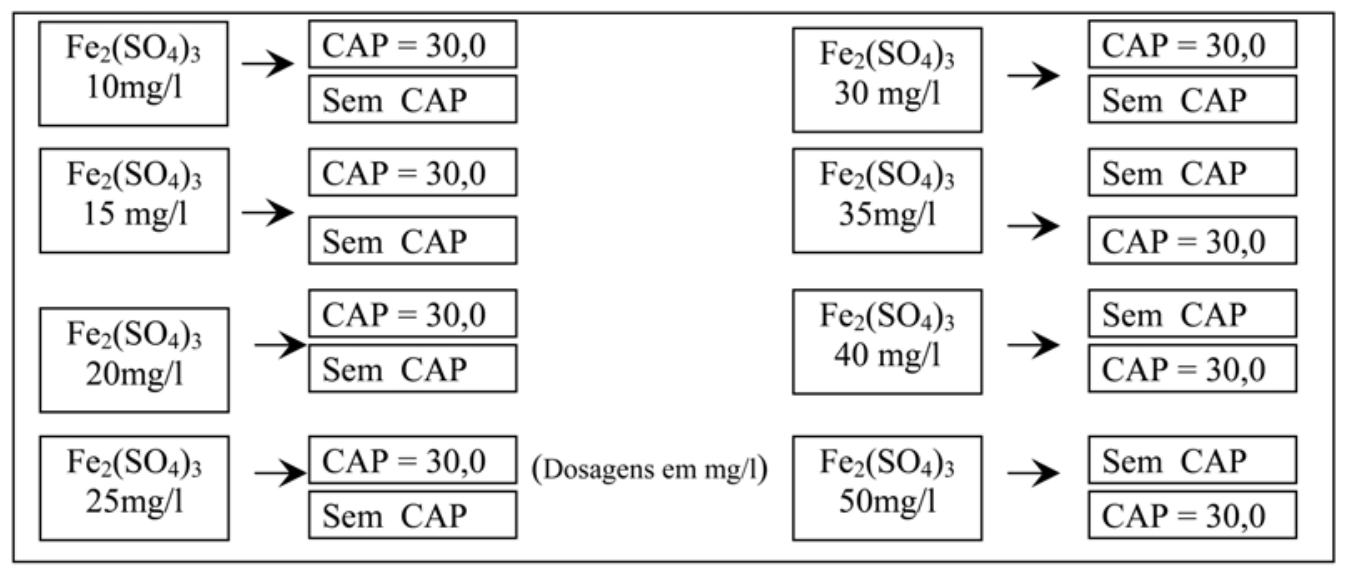

Figura 2 - Fluxograma dos ensaios cinéticos com aplicação de $30 \mathrm{mg} / \mathrm{l}$ de CAP e diferentes dosagens de $\mathrm{Fe}_{2}\left(\mathrm{SO}_{4}\right)_{3}$ realizados em jar test

Para cada dosagem de coagulante realizava-se um ensaio com 6 jarros, com pH de coagulação variando entre 4,5 a 10. A coleta de amostras era efetuada simultaneamente em todos os jarros para determinação de $\mathrm{pH}$ e turbidez. Com o propósito de avaliar a eficiência da remoção de CONs da água bruta durante o processo de coagulação-floculação, no final de cada ensaio de jar-test, o jarro que apresentou a melhor remoção de turbidez era selecionado para determinação de COD e MIB. Com o objetivo de evitar interferência de partículas coloidais e em suspensão nas análises de COD e MIB, as amostras eram previamente filtradas em membrana filtrante $0,45 \mathrm{~mm}$.

Todas as análises e determinaçōes referidas foram realizadas utilizando-se os equipamentos localizados no laboratório da ETA Rio Grande. As análises de MIB foram efetuadas com cromatógrafo gasoso associado a espectrofotômetro de massa (CG-MS-PAT) pelo laboratório de Química Orgânica da Companhia de Saneamento Básico do Estado de São Paulo (TCCL-SABESP). As análises de COD foram executadas no Laboratório de Análises Avançadas da Divisão de Controle Sanitário Centro (MCEC-SABESP) em equipamento SHIMATZUTOC5000A, de acordo com metodologia apresentada por Garzuzi et al (1999).

\section{APRESENTACÃO E ANALISE DOSS RESULTADOS EXPERIMENTAIS}

As figuras 3 e 4 (Ensaio 1), 5 e 6 (Ensaio 2) apresentam os resultados típicos de turbidez da água decantada obti- da para os ensaios de jar-test executados com diferentes dosagens de coagulante, com e sem a presença de CAP.

Comparando-se os resultados de turbidez da água decantada para os ensaios executados com e sem a aplicação de CAP, pode-se observar que a diferença dos resultados entre si é mínima, podendo afirmar que não houve prejuízo à qualidade da água decantada quando da aplicação de CAP para controle de gosto e odor.

Deve ser ressaltado que o CAP utilizado nos ensaios experimentais foi aplicado 1 minuto antes da adição do coagulante, o que garantiu que as partículas do material adsorvente tivessem sido capturadas pelo hidróxido metálico precipitado formado quando da adição do coagulante.

O ensaio 1 foi executado tendo a água bruta valores de turbidez da ordem de 2,0 UNT a 4,0 UNT, enquanto o ensaio 2 foi conduzido com valores de 1,3 UNT a 1,4 UNT. Comparando-se a Figura 3 (Ensaio 1 - $20 \mathrm{mg} \mathrm{Fe}_{2}\left(\mathrm{SO}_{4}\right)_{3} / \mathrm{L}$ ) e a Figura 5 (Ensaio 2 - $20 \mathrm{mg} \mathrm{Fe}_{2}\left(\mathrm{SO}_{4}\right)_{3} / \mathrm{L}$ ), pode-se observar que os valores de turbidez da água decantada variaram de 1,0 UNT a 1,6 UNT para o Ensaio 1, enquanto para o Ensaio 2 os seus valores ficaram entre 0,5 UNT e 1,0 UNT.

Uma vez que o coagulante empregado na ETA Rio Grande é um sal de ferro, este pode ser empregado em uma ampla faixa de $\mathrm{pH}$, podendo-se variar de 5,5 a 9,0. Em função das condiçôes operacionais da ETA e da qualidade da água bruta, pode ser mais interessante durantes certos períodos do ano operar o processo de coagulação em uma faixa de pH mais elevada (superior a 8,0), possibilitando assim a oxidação de ferro e manganês que porventura estejam presentes na água bruta quando houver a ocorrência de períodos de estratificação térmica no braço do Rio Grande (Reservatório Billings).

Pode-se observar que, para valores de $\mathrm{pH}$ de coagulação superiores a 8,0 não foram observados prejuízos na qualidade da água decantada, o que indica sua viabilidade de adoção quando necessário. No entanto, caso seja necessário buscar a otimização de remoção de CONs juntamente com a remoção de turbidez, podese notar que para valores de $\mathrm{pH}$ de coagulação inferior a 5,8, há uma ligeira queda na eficiência de remoção de turbidez, o que deverá requerer uma maior dosagem de coagulante (Figuras 5 e 6 ).

A importância do $\mathrm{pH}$ de coagulação na remoção de COD pode ser observada por intermédio das Figuras 7 e 8 nas quais são apresentados os resultados dos ensaios de jar-test conduzidos sem a aplicação de CAP para diferentes faixas de $\mathrm{pH}$.

Analisando-se a Figura 7, pode-se observar que os valores de remoção de COD para os ensaios de jar-test conduzidos com valores de $\mathrm{pH}$ de coagulação entre 8,0 e 9,0 situaram-se entre $15 \%$ e $20 \%$, valor este similar aos apresentados por Frederico et al (1999). Também se observa que, com o aumento da dosagem de coagulante, há um ligeiro acréscimo na remoção de COD, embora este seja bastante reduzido.

Por sua vez, observando-se os valores de remoção de COD para os ensaios de coagulação conduzidos em uma faixa de pH entre 5,8 a 6,5 (Figura 8), pode-se notar um maior aumento da remoção de COD, sendo este da ordem de $30 \%$ a $50 \%$. 


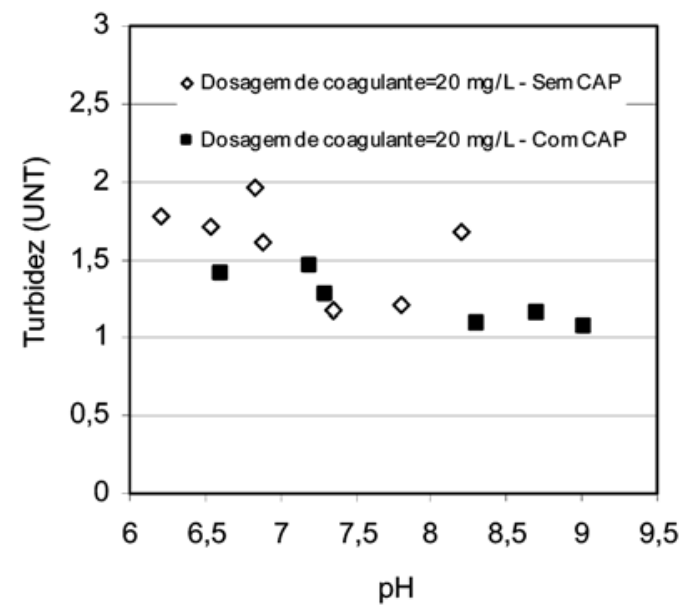

Figura 3 - Turbidez da água decantada em função do $\mathrm{pH}$ de coagulação para ensaios executados com e sem a aplicação de CAP. (Ensaio I)

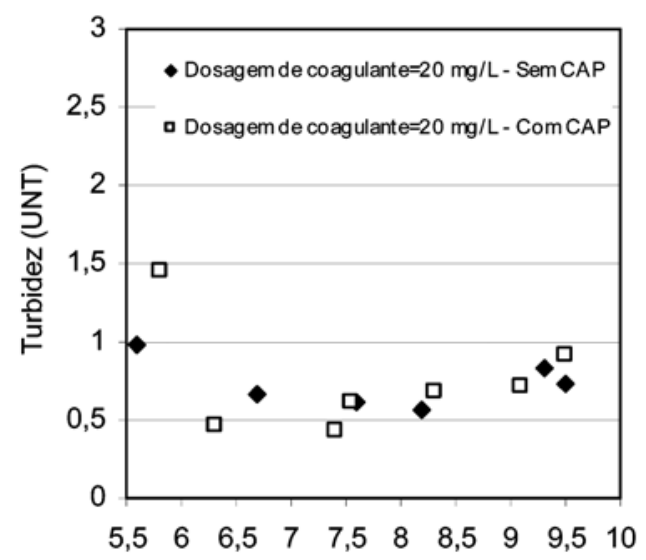

$\mathrm{pH}$

Figura 5 - Turbidez da água decantada em função do pH de coagulação para ensaios executados com e sem a aplicação de CAP. (Ensaio 2).

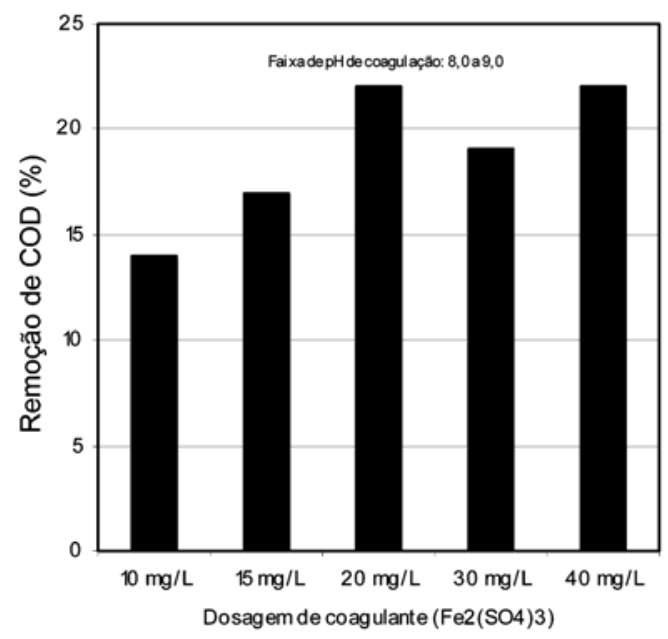

Figura 7 - Remoção de COD em função da dosagem de coagulante para os ensaios conduzidos sem a aplicação de CAP

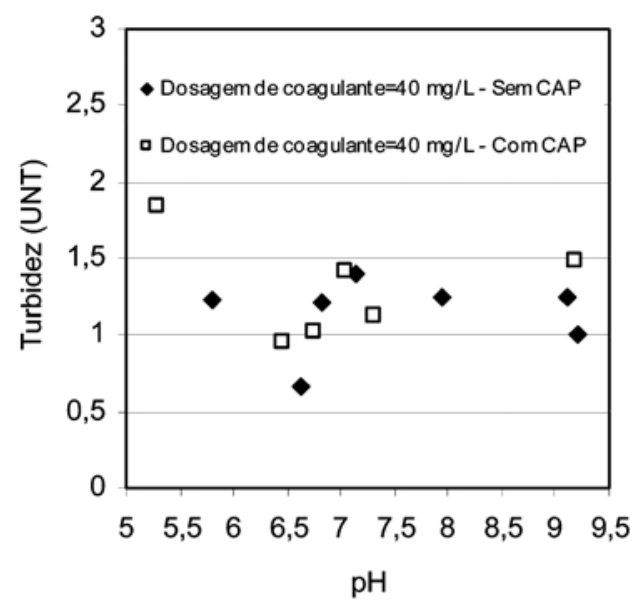

Figura 4 - Turbidez da água decantada em função do pH de coagulação para ensaios executados com e sem a aplicação de CAP (Ensaio I)

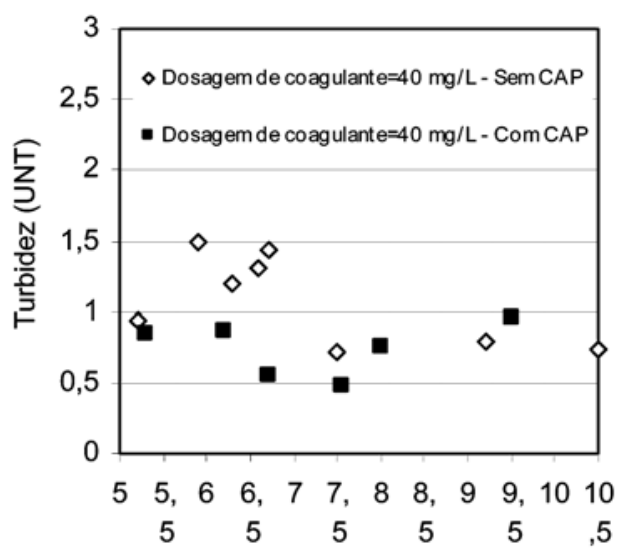

$\mathrm{pH}$

Figura 6 - Turbidez da água decantada em função do $\mathrm{pH}$ de coagulação para ensaios executados com e sem a aplicação de CAP. (Ensaio 2).

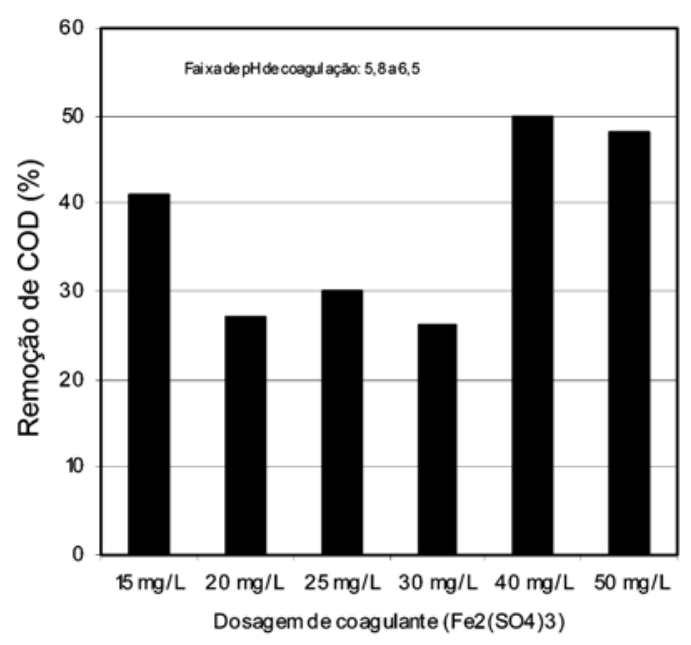

Figura 8 - Remoção de COD em função da dosagem de coagulante para os ensaios conduzidos sem a aplicação de CAP

Vol. I I - No I - jan/mar 2006, 7-I5 
Nota-se que os maiores valores de remoção de COD foram obtidos para dosagens de coagulante em torno de $40 \mathrm{mg} \mathrm{Fe}_{2}\left(\mathrm{SO}_{4}\right)_{3} / \mathrm{La} 50 \mathrm{mg} \mathrm{Fe}_{2}\left(\mathrm{SO}_{4}\right)_{3} / \mathrm{L}$, valores estes superiores aos requeridos para a maximização da remoção de turbidez. Os resultados confirmam os obtidos por demais pesquisadores que observaram que a faixa de $\mathrm{pH}$ de coagulação que proporciona a maximização da remoção de COD situa-se entre 5 e 6,5 (Semmens et al, 1980; Dempsey et al, 1984; Jacangelo et al, 1995).

Portanto, em função da necessidade da ETA maximizar a remoção de COD com vistas a permitir a diminuição da formação de SPD, muito provavelmente, a dosagem de coagulante a ser aplicada no processo de tratamento será determinada pela necessidade de remoção de COD e não pela redução da turbidez da água bruta.

Frequentemente, os CONs são denominados de substâncias húmicas, podendo estes ser classificados de acordo com a sua solubilidade em meio ácido ou alcalino. As substâncias húmicas são usualmente divididas em duas grandes categorias, a saber: ácidos húmicos, sendo estes solúveis em meio alcalino, mas insolúveis em meio ácido, e ácidos fúlvicos, solúveis tanto em meio alcalino como em meio ácido (Montgomery, 2005). Embora os ácidos húmicos e fúlvicos apresentem semelhanças estruturais, eles possuem grande diferença com relação a pesos moleculares, presença de grupos funcionais e proporção de carbono, oxigênio e nitrogênio.

Os ácidos fúlvicos apresentam pesos moleculares da ordem de 200 a 1.000 unidades de massa atômica, enquanto o peso molecular de determinados ácidos húmicos pode chegar até 200.000 unidades de massa atômica. As diferenças entre ambas as fraçōes que compõem os ditos compostos húmicos que, como já mencionado, variam desde seus pesos e tamanhos moleculares até a presença de grupos funcionais ionizáveis, são de fundamental importância no que diz respeito a sua estabilidade e reatividade em meio aquoso.

Conforme já salientado anteriormente, a análise dos resultados permite inferir que para a água bruta afluente a ETA Rio Grande foram obtidos resultados satisfatórios para a turbidez da água decantada com sais de ferro para uma ampla faixa de $\mathrm{pH}$. As dosagens de coagulantes utilizadas e a ampla faixa de variação do $\mathrm{pH}$ de coagulação, de 5,0 a 9,0, independente- mente da magnitude da dosagem do coagulante empregado, sugerem que, de acordo com Di Bernardo (1993), o processo de coagulação ocorre, preferencialmente, pelo mecanismo de varredura. Deste modo, a remoção de COD ocorre por mecanismo de coprecipitação, em que os CONs são adsorvidos no hidróxido metálico formado quando da adição do coagulante e, de acordo com evidências experimentais relatadas por diversos pesquisadores, as frações removidas com maior eficiência são as de maior peso molecular (ácidos húmicos) (AWWA, 1999).

Portanto, em face da remoção das maiores frações moleculares dos CONs por processos de coagulação química, a tendência é que as menores permaneçam na fase líquida. Caso a ETA tenha a necessidade de aplicar CAP para eventual controle de gosto e odor, dado que estas menores frações de CONs são mais susceptíveis de serem removidas por processos de adsorção, espera-se que haja uma redução na remoção de COD. As Figuras 9 e 10 apresentam os valores de remoção de COD para os ensaios de jar-test conduzidos com aplicação de CAP para diferentes faixas de $\mathrm{pH}$.

Comparando-se as Figuras 7 e 9 entre si, pode-se observar que a aplicação de CAP para os ensaios de coagulação conduzidos com $\mathrm{pH}$ na faixa ente 8,0 e 9,0 não propiciou um aumento na remoção de COD da fase líquida, sendo que as eficiências de remoção situaram-se na faixa de $15 \%$ a $25 \%$.

Do mesmo modo, comparando-se as Figuras 8 e 10, observa-se que também as faixas de remoção de COD da fase líquida para os ensaios de jar-test conduzidos com e sem CAP para uma faixa de $\mathrm{pH}$ de coagulação entre 5,8 e 6,5 situaram-se entre $40 \%$ e $50 \%$, não se tendo evidenciado nenhuma melhoria na eficiência de remoção de COD mediante a aplicação de CAP na água bruta.

Ressalta-se, portanto, que a otimização da remoção de CONs foi muito mais dependente do $\mathrm{pH}$ de coagulação do que a dosagem de coagulante. Em face da grande diversidade dos CONs presentes na fase líquida, tal conclusão não pode ser generalizada, embora o mesmo padrão de comportamento tenha sido observado para a água bruta proveniente do Reservatório do Guarapiranga e que abastece a ETA ABV, também localizado na RMSP (Frederico et al, 1999). Podese inferir que águas brutas provenientes de mananciais superficiais com elevado grau de eutrofização, formados por reservatórios de acumulação com elevado tempo de detenção hidráulico, possam ter este padrão de comportamento no tocante a remoção de CONs pelo processo de coagulação.

Tradicionalmente, a aplicação de CAP no tratamento de águas de abastecimento tem por finalidade garantir a remoção de compostos orgânicos sintéticos de origem antrópica e de origem biológica causadores de gosto e odor, não sendo aplicado para a remoção de $\mathrm{CON}$ s presentes na fase líquida, dado que as dosagens necessárias a serem aplicadas para que a sua remoção seja efetiva teriam que ser muito elevadas e proibitivas do ponto de vista econômico.

Como a melhor alternativa para a remoção de CONs no processo de tratamento de água ainda é a otimização do processo de coagulação, a aplicação do CAP passaria a ser otimizada com respeito à remoção de compostos orgânicos causadores de gosto e odor.

Embora não se tenha evidenciado nenhuma melhoria na remoção de COD quando da aplicação de CAP, uma vez que o processo de adsorção não é seletivo no tocante a remoção de compostos orgânicos específicos, é de se esperar uma redução na eficiência de remoção de MIB quando da presença de CONs pois enquanto estes encontram-se presentes na fase líquida em concentraçôes da ordem de $\mathrm{mg} / \mathrm{L}$, aqueles encontram-se na faixa $\mathrm{de} n \mathrm{ng} / \mathrm{L}$.

As figuras 11 e 12 apresentam os valores de eficiência de remoção de MIB na água bruta para os ensaios de coagulação efetuados com aplicação de CAP e diferentes dosagens de coagulante para faixas de $\mathrm{pH}$ de 8,0 a 9,0 e 5,8 a 6,5 respectivamente.

Pode-se observar que, tanto para os ensaios de coagulação conduzidos em faixas de $\mathrm{pH}$ entre 8,0 a 9,0 e 5,8 a 6,5, as eficiências de remoção de MIB situaramse na faixa de $50 \%$ a $60 \%$, independentemente da dosagem de coagulante e do $\mathrm{pH}$ de coagulação.

Uma vez que o tratamento convencional de águas de abastecimento não possui a capacidade de remover compostos orgânicos de baixo peso molecular, tipicamente característico de moléculas de MIB, não é de se esperar que haja aumento de eficiência de sua remoção com o aumento da dosagem de coagulante.

No entanto, uma maior dosagem de coagulante aplicado poderia proporcionar um aumento na remoção de CONs e, deste 


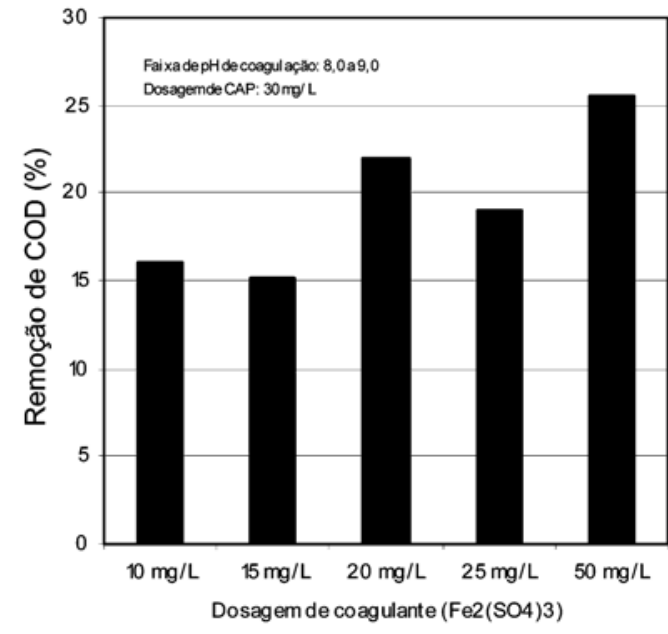

Figura 9 - Remoção de COD em função da dosagem de coagulante para os ensaios conduzidos com a aplicação de CAP

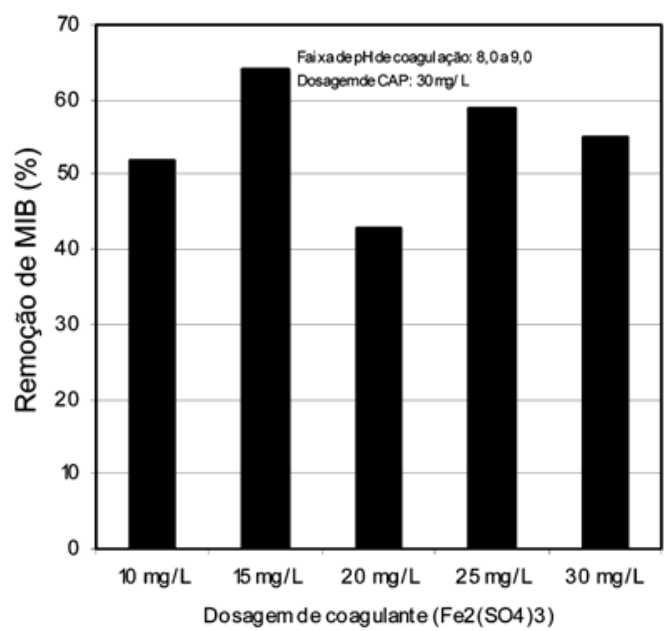

Figura II - Remoção de MIB em função da dosagem de coagulante para os ensaios conduzidos com a aplicação de CAP

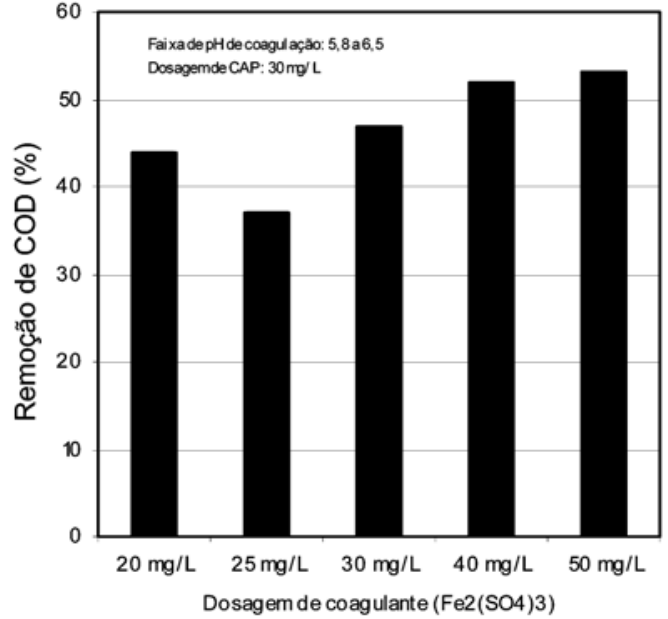

Figura 10 - Remoção de COD em função da dosagem de coagulante para os ensaios conduzidos com a aplicação de CAP

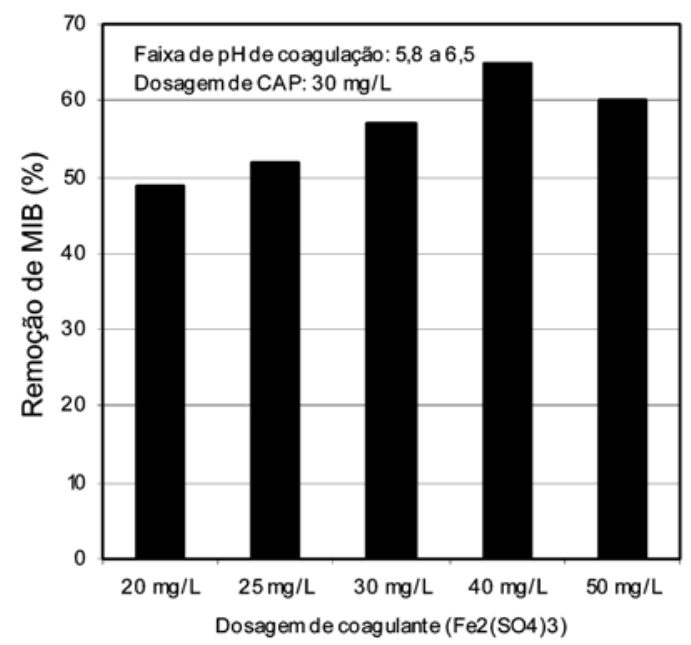

Figura I2 - Remoção de MIB em função da dosagem de coagulante para os ensaios conduzidos com a aplicação de CAP

modo, possibilitar uma maior eficiência na remoção de MIB. Como foi observado anteriormente que a influência da dosagem de coagulante na remoção de CONs é muito menor do que quando comparado com o $\mathrm{pH}$ de coagulação, a fração dos CONs passível de serem removida pelo processo de coagulação ocorre independentemente da dosagem de coagulante. Deste modo, os CONs residuais na fase líquida após o processo de coagulação tendem praticamente à mesma composição (concentração e peso molecular) e, assim sendo, sua influência no processo de adsorção tende a ocorrer igualmente para águas brutas coaguladas com dosagens de coagulante de $10 \mathrm{mg}$ $\mathrm{Fe}_{2}\left(\mathrm{SO}_{4}\right)_{3} / \mathrm{La} 50 \mathrm{mg} \mathrm{Fe}{ }_{2}\left(\mathrm{SO}_{4}\right)_{3} / \mathrm{L}$.

Conforme já comentado anteriormente, observa-se que, independente- mente do pH de coagulação, também as eficiências de remoção de MIB por processo de adsorção foram bastante similares entre si. No entanto, observou-se que na faixa de $\mathrm{pH}$ de coagulação de 5,8 a 6,5 houve uma maior remoção de COD quando comparado com os valores obtidos para a faixa de $\mathrm{pH}$ de coagulação de 8,0 a 9,0. Como as eficiências de remoção de MIB foram bastante semelhantes entre si, pode-se afirmar que as fraçōes dos CONs que porventura foram adsorvidos pelo CAP e que poderiam competir pelos mesmos sítios de adsorção com as moléculas de MIB não foram removidas pelo processo de coagulação.

Uma vez que as menores frações dos CONs são removidos de modo mais eficiente por processos de adsorção e suas maiores frações removidas por processos de coagulação, observa-se que, especificamente para a água bruta em questão, a otimização dos processos de remoção de COD por processos de coagulação e MIB por processos de adsorção não são competitivos entre si, ou seja, é possível a otimização do processo de adsorção sem que seja sacrificada a otimização da remoção de COD pelo processo de coagulação química.

Um aspecto interessante a ser observado é que os resultados de eficiência de remoção de MIB por adsorção em CAP obtidos para a água bruta proveniente do Reservatório Billings foram relativamente menores quando comparados com os obtidos para a água bruta do Reservatório Guarapiranga quando da condução de ensaios de adsorção sob as mesmas condições de tipo e dosagem de CAP e 
tempo de contato (Ferreira Filho et al, 2003).

Enquanto para a água bruta proveniente do Reservatório do Guarapiranga foram obtidos valores de remoção de MIB da ordem de $90 \%$ para dosagens de CAP da ordem de $30 \mathrm{mg} / \mathrm{L}$, as eficiências de remoção de MIB para a água bruta do Reservatório Billings não foram superiores a $60 \%$, o que evidencia a diferença entre a natureza dos $\mathrm{CONs}$ que possam estar presentes em ambas as águas brutas. Essa diversidade de características dos CONs (peso molecular, grupos funcionais, estrutura química, etc...), por terem influência direta nos processos de coagulação química e adsorção, precisaria ser melhor estudada e explorada quando da concepção, projeto e operação de futuras estações, pelo fato de constituírem-se em desafios na produção de água tratada, a fim de que a mesma venha a atender padrões de potabilidade mais restritivos que porventura sejam adotados no futuro.

\section{CONCLUSÕES E RECOMENDAÇỖES FINAIS}

Com base no exposto e em função dos resultados experimentais obtidos, pode-se concluir que:

- Com respeito à remoção de turbidez da água bruta, observou-se que a aplicação de CAP para controle de gosto e odor não apresentou prejuízo à qualidade da água decantada, tendo sido possível atingir valores satisfatórios de turbidez para uma ampla faixa de $\mathrm{pH}$ $(5,8$ a 9,0$)$.

- A maior eficiência de remoção de COD foi obtida para os ensaios de coagulação conduzidos em uma faixa de $\mathrm{pH}$ entre 5,8 a 6,5 , tendo sido esta da ordem de $30 \%$ a $50 \%$. Por sua vez, para o $\mathrm{pH}$ de coagulação entre 8,0 e 9,0 obteve-se uma remoção de COD na faixa de 15\% e 20\%.

- Os maiores valores de remoção de COD foram obtidos para dosagens de coagulante em torno de $30 \mathrm{mg} \mathrm{Fe}_{2}\left(\mathrm{SO}_{4}\right)_{3} / \mathrm{L}$ a $50 \mathrm{mg} \mathrm{Fe}{ }_{2}\left(\mathrm{SO}_{4}\right)_{3} / \mathrm{L}$, valores estes superiores aos requeridos para a maximi zação da remoção de turbidez. Portanto, em função da necessidade da ETA de maximizar a remoção de COD com vistas a permitir a diminuição da formação de SPD, muito provavelmente, a dosagem de coagulante a ser aplicada no processo de tratamento será determinada pela necessidade de remoção de COD e não pela redução da turbidez da água bruta.
- A aplicação de CAP para fins de controle de gosto e odor os ensaios de coagulação conduzidos com $\mathrm{pH}$ na faixa de 8,0 a 9,0 e 5,8 a 6,5 não propiciou melhoria na remoção de COD da fase líquida.

- Com respeito à remoção de MIB, para uma dosagem de CAP aplicada na água bruta de $30 \mathrm{mg} / \mathrm{L}$, as suas eficiências de remoção situaram-se na faixa de $50 \%$ a $60 \%$, independentemente da dosagem de coagulante e do $\mathrm{pH}$ de coagulação.

- Assim sendo, a operação do processo de coagulação na faixa de $\mathrm{pH}$ entre 5,8 e 6,5 permitiu, não somente a otimização do processo de coagulação na remoção de turbidez, mas também a remoção de COD e, dado que a remoção de MIB apresentou-se ser independente do $\mathrm{pH}$, os objetivos de otimização da ETA Rio Grande mostraram-se ser viáveis tecnicamente.

\section{AGRADECIMENTOS}

A FAPESP (Fundação de Amparo a Pesquisa do Estado de São Paulo) pelo suporte financeiro concedido (Bolsa de Pós-Doutoramento 2003/00536-6).

A SABESP, por permitir a realização da pesquisa nas dependências do Laboratório da Estação de Tratamento de Água do Rio Grande e pelas análises de MIB e COD.

\section{REFERÊNCIAS}

AWWA. Water Quality and Treatment. McGraw-Hill, 5a edição, 1.233 p., 1999.

AWWARF Optimization of powdered activated carbon application for geosmin and MIB removal. Denver., AWWA, 241 p., 2000.

BELLAR, T.A., LICHTENBERG, J.J., KRONER, R.C. The occurrence of organohalides in chlorinated drinking water. Journal American Water Works Association, pág 703-706, December, 1974.

DEMPSEY, B.A.; GANHO, R.M.; O’MELIA, C.R. The coagulation of humic substance by means of aluminum salts. Journal American Water Works Association, pág 141-150, April 1984.

DI BERNARDO, L. Métodos e técnicas de tratamento da água, Vol. 1, Rio de Janeiro, ABES, 496 p. 1993.

DI BERNARDO, L., DI BERNARDO, A., CENTURIONE FILHO, P.L. Ensaios de tratabilidade de água e dos residuos gerados em estaçôes de tratamento de água. São Carlos, Rima Editora, 237 p., 2002.

FERREIRA FILHO, S.S., FERNANDES, A.N Remoção de Compostos Orgânicos Causadores de Gosto e Odor em Águas de Abastecimento: Aplicação de Carvão Ativado em Pó. In: $22^{\circ}$ CONGRESSO BRASILEIRO DE ENGENHARIA SANITÁRIA E AMBIENTAL, Joinville, 2003.
FREDERICO, E.A., et al. Remoção de compostos orgânicos naturais no processso convencional de tratamento de água: influência do $\mathrm{pH}$ e da dosagem de coagulante na eficiência do processo. In: $20^{\circ}$ CONGRESSO BRASILEIRO DE ENGENHARIA SANITÁRIA E AMBIENTAL, Rio de Janeiro, 1999.

GARZUZI, M.P., et al. Remoção de compostos orgânicos naturais no processso convencional de tratamento de água: monitoramento da Estação de Tratamento de Água do Alto da Boa Vista $(E T A-A B V)$. In: $20^{-}$CONGRESSO BRASILEIRO DE ENGENHARIA SANITÁRIA E AMBIENTAL, Rio de Janeiro, 1999.

JACANGELO, J.G., et al. Select processes for removing NOM: an overview. Journal American Water Works Association, pág 64-77, January, 1995.

MONTGOMERY, J. Water treatment: principles and design. New York, John Wiley \& Sons, $2^{\mathrm{a}}$ Edição, 1.948 p., 2005.

ROOK, J.J. Haloforms in drinking water. Journal of American Water Works Association, pag 168-172, March, 1976.

SEMMENS, M.J.; FIELD, T.K. Coagulation: experiences in organic removal. Journal American Water Works Association, pág 476-483, August, 1980.

SINGER, P. C. Control of disinfection by-products in drinking water. Journal of Environmental Engineering, American Society of Civil Engineers, pag 727-744, July/August, 1994.

SONTHEIMER,H.; CRITTENDEN,J.C.; SUMMERS, R.S. Activated carbon for water treatment. DVGW Forschungsstelle EnglerBunte-Institut Universitat, Kalsruhe, 722 pag. 1988.

Endereço para correspondência:

Sidney Seckler Ferreira Filho

Departamento de Engenharia

Hidráulica e Sanitária

Escola Politécnica da Universidade

de São Paulo

Av. Prof. Almeida Prado, trav. 2, n.27I - Prédio de Engenharia Civil

Cidade Universitária

05508-900 São Paulo - SP - Brasil

Tel.: (I I) 309 I-5220/309 I-5444

Fax: (I I) 309 I-5423

E-mail:ssffilho@usp.br 